\title{
Simulation of Application of FGM Piezoelectric Actuators for Active Reduction of Beam Vibrations
}

\author{
U. FERDEK AND M.S. KOZIEŃ* \\ Cracow University of Technology, Institute of Applied Mechanics \\ al. Jana Pawła II 37, 31-864 Kraków, Poland
}

\begin{abstract}
In the paper results of simulation of active reduction of vibration of the free-fixed beam by piezoelectic actuators made of functionally graded materials are presented. The aim of simmulation was to estimate sensitivity of the process of reduction. The effect of the level of gradation of material properties and amplitude of the applied voltage on effectiveness of the reduction process was analyzed. The analysis was reduced to the case of excited vibrations of the first mode and was performed by application of the finite element package Ansys.
\end{abstract}

DOI: 10.12693/APhysPolA.123.1044

PACS: 33.15.Mt, 34.50.Ez, 77.22.Gm

\section{Introduction}

In recent years there has been an increasing interest in application of functionally graded materials (FGM) in mechanical structures, especially those working in extreme thermal conditions, e.g. wheel brake components [1-4]. They are intended to reduce delamination process in areas of contact between two types of materials with different properties, especially varying with temperature or due to existing thermal stress in these regions. Piezoelectric elements are commonly used to reduce vibrations of beam- and surface-like structures [5-11]. During vibrations, deformations of the structure and piezoelectric actuators are dynamic processes. Due to different elastic properties, the extra stress in the region of contact (usually the glue film) may arise and start the delamination process. Contemporary technologies offer possibility to product pizoelectric elements with material properties variable along their thickness. There exist papers in which application of piezoelectric graded materials to reduce beam vibrations is discussed. As representative examples, one can mention the studies [12-14].

For several years, the present authors have carried out some FEM simulations of active and passive reduction of vibrations by piezoelectric elements $[9,10]$. In a natural way, the problem of sensitivity of a system to different variations of piezoelectric properties is interesting in view of possible practical applications. The aim of the paper was to estimate the effect of vibration reduction by application of the piezoelectric functionally graded elements with different level of material gradation. Simulations were carried out by application of the finite element package Ansys for a fixed-free beam and the first natural mode.

\section{Functionally graded materials}

The history of functionally graded materials started in the USA (MIT article in 1971 and patent in 1972). Fur-

\footnotetext{
*corresponding author; e-mail: kozien@mech.pk.edu.pl
}

ther technological progress was made in Japan in 1984 and Switzerland in 1985 [15]. The general idea of functionally graded materials is to product a material properties of which are continuously changing in a selected direction. Finally on one side (edge) of FGM, the material properties are similar to properties of material to which this edge is connected (glued). The properties on opposide side are completely other. For piezoelectric actuators, one side should have the properties similar to material in contact, e.g. to steel or aluminum, and the opposite one is the pure piezoelectric material. Therefore the general result of its application is reduction of stress concentration in the place of mounting.

The linear constitutive equations for the unbounded piezoelectric material have the form [16]

$$
\left\{\begin{array}{l}
\underline{T}=\underline{c} \cdot \underline{S}-\underline{e} \cdot \boldsymbol{E} \\
\boldsymbol{D}=\underline{e}^{T} \cdot \underline{S}+\underline{\varepsilon} \cdot \boldsymbol{E}
\end{array},\right.
$$

where $\underline{T}$ - is the stress tensor in Voigt's vector notation, $\underline{S}$ - is the strain tensor in Voigt's vector notation, $\boldsymbol{D}$ is the electric displacements vector, $\boldsymbol{E}$ - is the electric field vector, $\underline{\varepsilon}$ - is the permittivity constants matrix, $\underline{e}$ is the piezoelectric constants matrix, and $\underline{c}$ - is the elastic constants matrix (the elasticity matrix).

In general, finite graded material is a non-homogeneous one. Therefore, components of matrices $\underline{\varepsilon}, \underline{e}$ and $\underline{c}$ describing the material properties are in general functions of position in the material. In literature there exist two useful relationships to describe one-directional continuous variability of the material properties: the exponential one (2) - e.g. Noda [2], and the power-type one, generally connected with the volume ratio of the components (3) - e.g. Ootao [3],

$$
\begin{aligned}
& E(z)=E_{0} \exp \left(a \frac{z}{z_{0}}\right), \\
& E(z)=E_{0}\left(b \frac{z}{z_{0}}\right)^{\alpha},
\end{aligned}
$$

where $z$ is the parameter along which the material properties are varying, $z_{0}$ is the characteristic value of the parameter $z, E$ is the considered property, and $E_{0}, a, b$, and 
$\alpha$ are the material constants. W.M. Rubio et al. [17, 18] describe in their simulations the one-directional variation of material properties as a linear function of $z$.

\section{FEM simulation}

Simulation was carried out for fixed-free beam with length $0.3 \mathrm{~m}$, width $0.03 \mathrm{~m}$, and height $0.002 \mathrm{~m}$, made of aluminum. The piezoelectric actuators of dimension $0.02 \mathrm{~m} \times 0.02 \mathrm{~m} \times 0.001 \mathrm{~m}$ existing in pairs were distant $0.03 \mathrm{~m}$ and $0.15 \mathrm{~m}$, respectively, from the fixed end. The first single piezoelectric element $0.24 \mathrm{~m}$ from the fixed end was a sensor. Geometry of the system was visualized by the finite element model and is shown in Fig. 1.

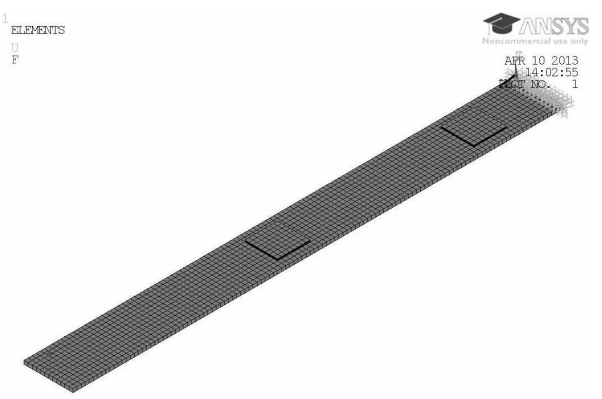

Fig. 1. Geometry of the beam in FEM model.

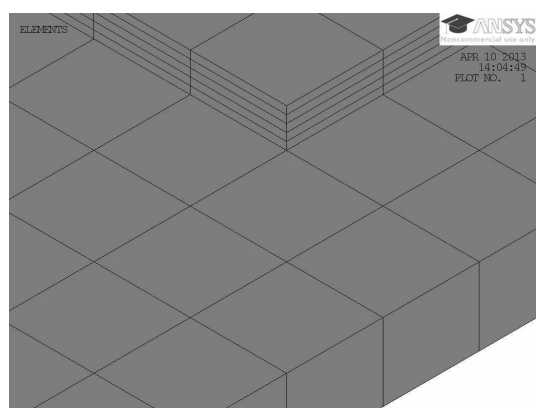

Fig. 2. FEM mesh of piezoelectric actuators.

The elastic constants matrix (4), the piezoelectric constants matrix (5), and the permittivity constants matrix (6) are assumed in the given forms, where the suitably matrices for homogeneous FGM material are $\underline{c}_{\text {hom }}$, $\underline{e}_{\text {hom }}$, and $\underline{\varepsilon}_{\text {hom }}$ (NEPEC). Variable $z$ describes the distance from one piezoelectric element edge belonging to the beam, along the line of changing of the piezoelectric properties and $z_{0}$ was assumed as equal to $0.001 \mathrm{~m}$ (distance from the middle axis of a beam to piezoelectric element edge belonging to the beam). The qualitative properties of functionally graded material were described based on the article [13] by the asssumed values of coeffitents: 0.085 in (4), 0.322 in (5) and 0.106 in (6). Variable parameter $k$ describes the level of gradation, and it takes arbitrarily chosen values. Piezoelectric element was divided in FEM model into five levels of elements with different graded material properties, as shown in Fig. 2.

$$
\begin{aligned}
& \underline{c}_{F G M}=\underline{c}_{\mathrm{hom}} \exp \left(0.085 k \frac{z}{z_{0}}\right), \\
& \underline{e}_{F G M}=\underline{e}_{\mathrm{hom}} \exp \left(0.322 k \frac{z}{z_{0}}\right) \\
& \underline{\varepsilon}_{F G M}=\underline{\varepsilon}_{\mathrm{hom}} \exp \left(0.106 k \frac{z}{z_{0}}\right)
\end{aligned}
$$

Vibrations of the beam was excited by harmonically variable concentrated force with amplitude $F_{0}=1 \mathrm{~N}$ applied to the free end of the beam. The response of the beam was detected in the control point distant $0.08 \mathrm{~m}$ from the fixed end. Only the first mode of vibrations was considered. The mode shape is shown in Fig. 3.

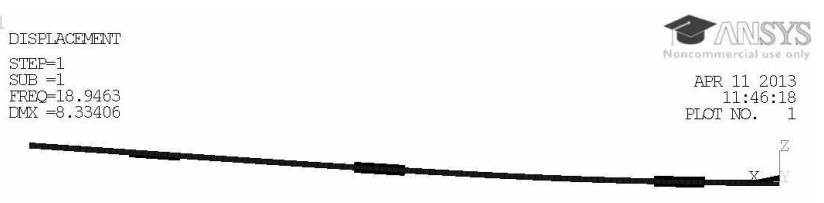

Fig. 3. Form of the first mode.

Two groups of simulations were performed:

- homogeneous piezoelectric material with basic properties,

- graded piezoelectric material with properties varying according to relationsips (4), (5), and (6), where $\underline{c}_{\mathrm{hom}}, \underline{e}_{\mathrm{hom}}$, and $\underline{\varepsilon}_{\mathrm{hom}}$ are the values for based homogeneous material NEPEC:

$$
\begin{aligned}
& \underline{e}_{\mathrm{hom}}=\left[\begin{array}{ccc}
0 & 0 & -4.1 \\
0 & 0 & -4.1 \\
0 & 0 & 14.1 \\
0 & 0 & 0 \\
0 & 10.5 & 0 \\
10.5 & 0 & 0
\end{array}\right] \frac{\mathrm{C}}{\mathrm{m}^{2}}, \\
& \underline{\varepsilon}_{\mathrm{hom}}=\left[\begin{array}{ccc}
804.6 & 0 & 0 \\
0 & 804.6 & 0 \\
0 & 0 & 569.7
\end{array}\right] \cdot 8.854 \frac{\mathrm{pF}}{\mathrm{m}} .
\end{aligned}
$$$$
c_{\text {hom }}=\left[\begin{array}{cccccc}
13.2 & 7.1 & 7.3 & 0 & 0 & 0 \\
0 & 13.2 & 7.3 & 0 & 0 & 0 \\
0 & 0 & 11.5 & 0 & 0 & 0 \\
0 & 0 & 0 & 3.0 & 0 & 0 \\
0 & 0 & 0 & 0 & 2.6 & 0 \\
0 & 0 & 0 & 0 & 0 & 2.6
\end{array}\right] \cdot 10^{10} \frac{\mathrm{N}}{\mathrm{m}^{2}},(7)
$$

Some arbitrarily chosen values of parameter $k$ which describe the level of gradation were considered. Amplitude of voltage has been changed in the simulation in the range $[0,1500] \mathrm{V}$. The range was assumed so to find the optimal value of the amplitude, in comparison with the amplitude of excitation and response of the structure. 
The maximum realistic value of voltage amplitude was about $400 \mathrm{~V}$. The frequency response functions in the control point for the case of $k=5$ are shown in Fig. 4 (no voltage activation) and Fig. 5 (active control for voltage amplitude $250 \mathrm{~V}$ ). In Table, results of reduction of vibration in the control point are presented for amplitude of voltage equal to $250 \mathrm{~V}$. The effectiveness of vibration reduction for the three chosen values of the parameter of gradation, $k=0$ (homogeneous material), $k=5$, and $k=10$, as a function of voltage amplitude is shown in Fig. 6. The parameter of effectivenes of reduction $w_{\text {eff }}$ is defined as

$$
w_{\text {eff }}=\frac{w_{0}-w_{u}}{w_{0}} \times 100[\%],
$$

where $w_{0}$ is the value of amplitude of displacement in control point for voltage amplitude $V=0$ and $w_{u}$ is the same value of amplitude of displacement for voltage amplitude $V=u$.

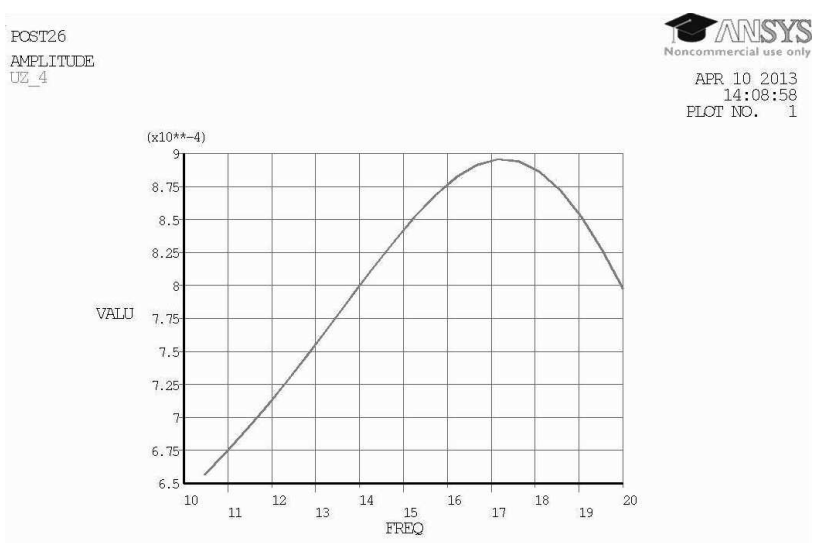

Fig. 4. FRF function of displacement for control point $-k=5, V=0 \mathrm{~V}$.

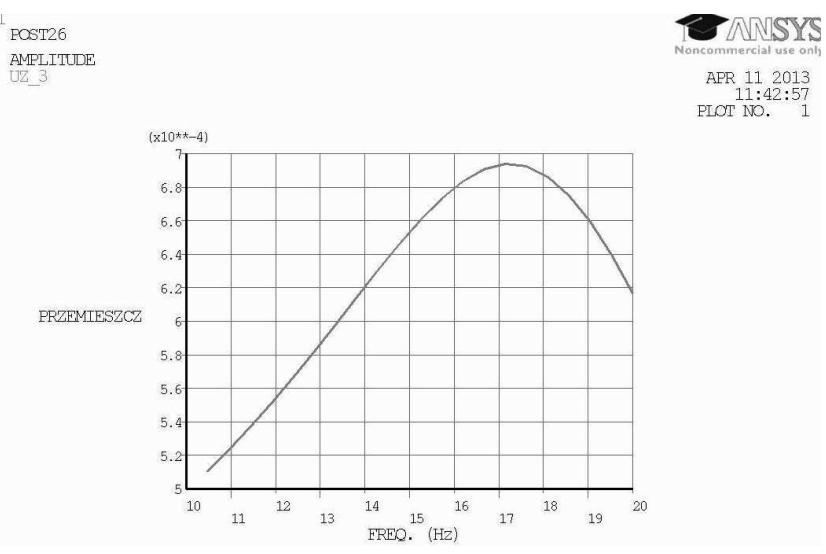

Fig. 5. FRF function of displacement for control point $-k=5, V=250 \mathrm{~V}$

Results of analyses show that the vibration reduction effectiveness varies insignificantly after application of the FGM material in comparison with the homogeneous ma-
TABLE

Level of reduction of vibrations in control point

\begin{tabular}{c|c|c|c|c}
\hline \hline \multirow{2}{*}{ material } & \multirow{2}{|c|}{$k$} & \multicolumn{2}{|c|}{$\begin{array}{c}\text { displacement }[\mathrm{mm}] \\
\text { before }\end{array}$} & \multirow{2}{*}{$w_{\text {eff }}$} \\
& & \multicolumn{2}{|c|}{ after } & \\
\hline hom & 0 & 0.909 & 0.739 & 18.7 \\
FGM & 1 & 0.907 & 0.723 & 20.3 \\
FGM & 5 & 0.892 & 0.689 & 22.8 \\
FGM & 10 & 0.879 & 0.716 & 18.5 \\
FGM & 20 & 0.858 & 0.771 & 10.1
\end{tabular}

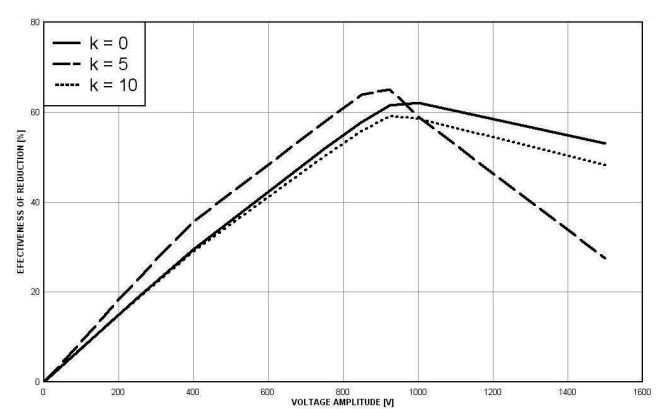

Fig. 6. The vibration reduction effectiveness for different values of parameter $k$ as a function of voltage amplitude.

terial, for the considered values of $k$. There was no clear relationship between value of $k$ and values of effectiveness of reduction for the considered values of $k$.

\section{Conclusions}

- It is possible to consider application of the FGM type actuators due to reduction of stress in contact region.

- The obtained level of reduction after application of FGM actuators changes insignificantly in comparison to the homogeneous one.

- When FGM actuators are applied, the problem of optimization of the gradation level arises.

\section{Acknowledgments}

The presented analyses were performed during realisation of the State Committee for Scientific Research grant No. N N504 078038.

make

[1] S. Hernik, J. Appl. Math. Mech. - ZAMM 89, 88 (2009).

[2] N. Noda, Z.H. Jin, Journal of Solids and Structures 30, 1039 (1993). 
[3] Y. Ootao, T. Akai, Y. Tanigawa, Proc. International Congress of Thermal Stresses, Vienna 2005, p. 709.

[4] J. Skrzypek, A. Ganczarski, S. Hernik, H. Egner, Advanced Material and Structures for Extreme Operating Conditions, Springer, Berlin 2008.

[5] A. Brański, M. Borkowski, S. Szela, Acta Phys. Pol. A 118, 17 (2010).

[6] A. Brański, G. Lipiński, Acta Phys. Pol. A 119, 936 (2011).

[7] S.P. Elliott, P.A. Nelson, Active control of vibrations, Academic Press, London 1997.

[8] R. Filipek, J. Wiciak, Eur. Phys. J. J. Special Topics 154, 57 (2008).

[9] M.S. Kozień, B. Koltowski, Acta Phys. Pol. A 119, 1005 (2011).

[10] M.S.Kozień, J. Wiciak, Acta Phys. Pol. A 116, 348 (2009).

[11] S.O.R. Moheimani, A.J. Fleming, Piezoelectric transducers for vibration control and damping, Springer, London 2006.
[12] M. Pietrzakowski, Mech. Mech. Eng. 10, 117 (2006).

[13] M. Pietrzakowski, Mechanics 26, 187 (2007).

[14] M. Pietrzakowski, Mach. Dynam. Probl. 32, 78 (2008).

[15] J. Rudel, Functionally Graded Materials. Properties, Modeling and Applications, KMM-NoE, Warszawa 2006.

[16] A. Erturk, D.J. Inman, Piezoelectric energy harvesting, Wiley, Chichester 2011.

[17] W.M. Rubio, F. Buiochi, J.C. Adamowski, E.C.N. Silva, Ultrasonics 49, 484 (2009).

[18] W.M. Rubio, F. Buiochi, J.C. Adamowski, E.C.N. Silva, Phys. Proced. 3, 891 (2010). 